Original article

\title{
Analogy of Del Nido and conventional cardioplegia in patients undergoing isolated mitral valve replacement surgery: A single-center retrospective study
}

\author{
Guruprasad Rai $^{\mathrm{a}, *}$, Ramesh Chandrababu ${ }^{\mathrm{b}, * *}$, Ganesh Sevagur Kamath ${ }^{\mathrm{a}}$, Shivashankar Pai B ${ }^{\mathrm{c}}$ \\ ${ }^{a}$ Department of Cardiovascular \& Thoracic Surgery, Kasturba Medical College, Manipal Academy of Higher Education, Manipal, Karnataka, 576104, India \\ b Department of Medical Surgical Nursing, Sri Ramachandra Faculty of Nursing, Sri Ramachandra Institute of Higher Education and Research, Porur, Chennai, 600116, \\ India \\ ${ }^{\mathrm{c}}$ Department of Perfusion Technology, Manipal College of Health Professions, Manipal Academy of Higher Education, Manipal, 576104, Karnataka, India
}

\section{A R T I C L E I N F O}

\section{Keywords:}

Cardiac surgical procedures

Cardioplegic solutions

Del nido cardioplegia

Cardiopulmonary bypass

Mitral valve replacement

Myocardial protection

\begin{abstract}
A B S T R A C T
Objective: The objective of this study was to assess the postoperative outcomes after utilizing the Del Nido cardioplegia as compared to conventional cardioplegia, in patients undergoing isolated mitral valve replacement surgery.

Methods: This was a single-center retrospective study conducted with the data from 80 patients with mitral valve disease, who underwent cardiopulmonary bypass. The outcome assessments of the Del Nido group $(n=40)$ was compared with that of the non-Del Nido group $(n=40)$. Various time factors were analyzed as end points that included cardiopulmonary bypass time aortic cross clamp time, duration of mechanical ventilation, need for postoperative inotropic support, volume of packed red blood cells (RBCs) transfusion, length of ICU and hospital stay, among others.

Results: The current study showed that the mean cardiopulmonary bypass time and aortic cross-clamp time were significantly shorter in the Del Nido group when compared to the non-Del Nido group $(\mathrm{P}<0.05)$. The mean number of packed red blood cell pints administered in the Del Nido group was fewer than the non-Del Nido group ( $\mathrm{P}<0.05)$. No significant differences found in other outcome measures.

Conclusion: The use of the Del Nido cardioplegia technique did significantly reduce the aortic cross-clamping time and cardio-pulmonary bypass time. The present study did also show a marked reduction in the amount of packed RBCs transfusion in the Del Nido group as compared to non-Del Nido conventional cardioplegia. Rigorous, adequately scrutinized randomized control trials are required to reiterate these findings in-order to enable us to extrapolate their benefits to a larger population.
\end{abstract}

\section{Introduction}

The concept of cardioplegia was introduced by Melrose to arrest the heart electively in the year $1955 .{ }^{1}$ Eventually, in 1973, Gay and Ebert came up with the new formula of crystalloid CP with much lesser concentration of Potassium Chloride ( $\mathrm{KCl})$, just enough to electromechanically stop the heart. ${ }^{2}$ These studies subsequently led to the clinical use of St. Thomas solution in 1976. In early 1990, researchers at The University of Pittsburgh found out a novel solution for myocardial protection. The team, led by Dr. Pedro J DEL NIDO, Hung Cao-Danh, K. Eric
Sommers, and Akihiko Ohkado, subsequently patented this solution, which is currently called the Del Nido cardioplegia. ${ }^{3}$

Conventional CP for infants and pediatric were similar to those used in patients except for the adjustment in volume, flow and pressure. ${ }^{4,5} \mathrm{~A}$ more recently developed cardioplegia solution, viz. Del Nido cardioplegia, which remained to protect infants and pediatric myocardium alike, could be of benefit for adult population, due to the similarities that immature and senescent hearts share with respect to their increased tendency for myocyte injury during ischemia and reperfusion.

In spite of a proven benefit in the usage of Del Nido cardioplegia in

\footnotetext{
* Corresponding author.

** Corresponding author. Department of Medical Surgical Nursing, Sri Ramachandra Faculty of Nursing, Sri Ramachandra Institute of Higher Education and Research, Porur, Chennai, 600116, India.

E-mail addresses: guru.rai@manipal.edu (G. Rai), ramesh.c@sriramachandra.edu.in (R. Chandrababu), kamath.ganesh@manipal.edu (G. Sevagur Kamath).
} 
pediatric population, surgical units for decades, have not tested its efficacy in adult cardia. Antegrade Single-dose, Del Nido cold blood CP could be used for antegrade delivery. Due to the ease of its administration and increased periods of redosing, Del Nido CP usage has been the rise in adult cardiac setup. ${ }^{6,7}$ This present study was aimed at comparing the Del Nido and conventional cardioplegia techniques in an attempt to find a feasible alternate for myocardial preservation, which may help to alleviate peri-operative ischemic injury/reperfusion injury and help to cut-short post-operative recovery period and hospital stay.

\section{Methods}

The study was conducted at a tertiary care hospital utilizing the clinical data of adult patients who underwent isolated mitral valve replacement for mitral stenosis (MS) or mitral insufficiency (MI). The study population was dichotomized into two groups based on the type of cardioplegia administered during the surgery; i.e. conventional cardioplegia (non-Del Nido group) $(n=40)$ and Del Nido cardioplegia (Del Nido) $(n=40)$. This was an observational retrospective study conducted between 2014 and 2017. The study included a total sample size of 80 patients based on the convenience sampling method and the samples who were eligible based on the inclusion criteria for the study were included. Patients in cardiogenic shock, following a concomitant cardiac surgical procedure or having active endocarditis were excluded from this study. The variables analyzed were peri-operative cardiopulmonary bypass time, aortic cross clamp time, duration of mechanical ventilation, and volume of packed red blood cells transfusion, length of ICU and hospital stay. Institutional Research Committee and Institutional Ethical Committee clearance were obtained prior to conducting the study.

The cardioplegia delivery method was mainly antegrade through the aortic route. Del Nido solution was a mixture of 4 parts of crystalloid solution to 1 part of oxygenated blood drawn from the oxygenator. The composition of the cardioplegic in the crystalloid part is given in the table below (Table 1). This cardioplegia is given as a single induction dose of $1 \mathrm{~L}$ which is cold (temperature of around $6-8{ }^{\circ} \mathrm{C}$ ), this does not require re-dosing for up to a period $60-80 \mathrm{~min}$. Re-dosing, if needed after $60-80 \mathrm{~min}$, can be given by a maintenance dose which will be half the volume of the induction dose. Ultrafiltration performed in all patients in Del Nido group.

Conventional cardioplegia, alternatively, is a mixture of 1 part of crystalloid solution with 4 parts of oxygenated blood drawn from oxygenator. A comparative between the compositions of cardioplegia in the crystalloid part between the two groups is given in Table 1. In this technique, the cardioplegia is given in an induction dose of $1 \mathrm{~L}$, which is cold, and temperature is maintained in the range of $5-8{ }^{\circ} \mathrm{C}$ and maintenance dose was repeated every $20 \mathrm{~min}$ with half the induction dose.

SPSS (version 16) package was used for data analysis. All quantitative data were coded and transformed to an excel master sheet for computer programming. Descriptive statistics were used to report all outcome variables. Chi-square test was done to assess the categorical data. For continuous data independent $t$-test was used as data were

Table 1

Composition of cardioplegia solutions.

\begin{tabular}{lll}
\hline Composition & del Nido cardioplegia & $\begin{array}{l}\text { Conventional } \\
\text { cardioplegia }\end{array}$ \\
\hline Carrier & $\begin{array}{l}1 \mathrm{~L} \text { plasmalyte base solution with } \\
\text { pH } 7.4\end{array}$ & $1 \mathrm{~L}$ Ringer Lactate \\
Blood: Clear & $1: 4$ & $4: 1$ \\
KCl & $26 \mathrm{mmol}(13 \mathrm{ml})$ & $16 \mathrm{mmol}(1.19 \mathrm{~g})$ \\
NaHCO3 & $26 \mathrm{mmol}(13 \mathrm{ml})$ & $20 \mathrm{mEq}(20 \mathrm{mmol})$ \\
Mannitol & $16.3 \mathrm{ml}$ & $20 \mathrm{ml}$ \\
Lidocaine $2 \%$ & $6.5 \mathrm{ml}$ & - \\
MgSO4 & $8 \mathrm{mmol}(4 \mathrm{ml})$ & $16 \mathrm{mmol}(3.25 \mathrm{~g})$ \\
Procaine & - & $1 \mathrm{mmol}(0.27 \mathrm{~g})$ \\
$\quad$ hydrochloride & & \\
\hline
\end{tabular}

normally distributed. For all data analyses, $\mathrm{p}<0.05$ was considered as statistically significant.

\section{Results}

Preoperative patient characteristics are presented in Table 2. There was no statistical significance, in terms of characteristics between two groups. The mean age of patients was 67.65 , and the indications for surgery were mitral stenosis $\mathrm{N}=53(66.25 \%)$ and or mitral regurgitation $\mathrm{N}=27$ (33.75\%). All mitral surgeries were completed with standard general anesthesia, employing cardiopulmonary bypass with trivial systemic hypothermia $\left(30-34{ }^{\circ} \mathrm{C}\right)$ thorough the median sternotomy approach.

Cardiopulmonary bypass time in the Del Nido cardioplegia was significantly lesser than patients in the conventional cardioplegia $60 \pm$ 10.5 mins and $90 \pm 13.5$ mins respectively with $\mathrm{P}<0.05$. Aortic crossclamp time was also relatively lesser in the Del Nido group $50 \pm 15.5$ and $70 \pm 20.5$ as compared to the conventional group.

The conventional group significantly had higher volume of initial dose of cardioplegia solution compared to the Del Nido group. Additional doses of cardioplegia administered were $1.0 \pm 0.4$ patients and $3.2 \pm 1.3$ patients respectively in the Del Nido and the conventional group. The total volume of solution administered in the Del Nido group was very less that in the conventional group with the statistical significance $(\mathrm{P}=0.001)$ (Table 3$)$.

Inotropic support was required for $26(65 \%)$ patients in the Del Nido group and for the conventional group $28(70 \%)$ patients $(\mathrm{p}=0.152)$. Use of dosages of postoperative inotropes used were same between the groups. None of the patient required a postoperative intra-aortic balloon pump. Vasoactive ionotropic score did not show any statistically significant disparity.

In terms of duration of mechanical ventilation, this was almost identical in the two groups ( $\mathrm{p}=0.373$ ). There was no statistical significance ( $\mathrm{p}=0.033$ with respect to total PRBC transfusion units (mean) between the Del Nido group ( $1.3 \pm 1.5)$ and the conventional group (2.3 \pm 2.4 ) were administered in the intra- and/or postoperative period (Table 4). There was no postoperative cerebrovascular accident and mortality occurred in either group. There was no statistically significant difference in the duration of intensive care unit stay and the number of days of stay in the hospital between the two groups.

\section{Discussion}

Even though the Del Nido cardioplegia has been in use for pediatric heart surgery for decades, its use in adult surgery is comparatively a developing concept. The conventional cardioplegia technique has been widely used in adult cardiac surgery as a standard for myocardial

Table 2

Preoperative patient demographics.

\begin{tabular}{|c|c|c|c|c|c|}
\hline \multicolumn{6}{|l|}{$\mathrm{N}=80$} \\
\hline \multirow{3}{*}{$\begin{array}{l}\text { Characteristics } \\
\text { Age (mean } \pm \mathrm{SD} \\
\text { years) }\end{array}$} & \multirow{2}{*}{\multicolumn{2}{|c|}{$\begin{array}{l}\text { del Nido group }(n=40) \\
66.6 \pm 13.5\end{array}$}} & \multirow{2}{*}{\multicolumn{2}{|c|}{$\begin{array}{l}\text { Conventional Group }(\mathrm{n}= \\
40) \\
68.7 \pm 11.7\end{array}$}} & \multirow{3}{*}{$\begin{array}{l}\mathrm{p} \\
\text { value } \\
0.47 \\
\end{array}$} \\
\hline & & & & & \\
\hline & Frequency & Percentage & Frequency & Percentage & \\
\hline \multicolumn{6}{|l|}{ Gender } \\
\hline Male & 30 & 75 & 26 & 65 & \multirow[t]{3}{*}{0.32} \\
\hline Female & 10 & 25 & 14 & 35 & \\
\hline \multicolumn{5}{|l|}{ Comorbidityr } & \\
\hline Hypertension & 34 & 85 & 32 & 80 & \multirow[t]{2}{*}{0.55} \\
\hline Diabetes & 22 & 55 & 18 & 45 & \\
\hline \multicolumn{6}{|c|}{ Indications for operation } \\
\hline Mitral stenosis & 29 & 72.5 & 24 & 60 & \multirow[t]{2}{*}{0.23} \\
\hline $\begin{array}{l}\text { Mitral } \\
\text { regurgitation }\end{array}$ & 11 & 27.5 & 16 & 40 & \\
\hline
\end{tabular}


Table 3

Operative and perfusion data.

\begin{tabular}{lllll}
\hline $\mathrm{N}=80$ & & & & \\
\hline Outcome measures & $\begin{array}{l}\text { del Nido } \\
\text { group }(\mathrm{n} \\
=40)\end{array}$ & $\begin{array}{l}\text { Conventional } \\
\text { group }(\mathrm{n}=40)\end{array}$ & $\begin{array}{l}\mathrm{t} \\
\text { value }\end{array}$ & $\begin{array}{l}\mathrm{p} \\
\text { value }\end{array}$ \\
\hline $\begin{array}{l}\text { Cardiopulmonary bypass } \\
\quad \text { time (mean } \pm \text { SD minutes) }\end{array}$ & $\begin{array}{l}60 \pm \\
10.5\end{array}$ & $90 \pm 13.5$ & 11.09 & 0.001 \\
$\begin{array}{l}\text { Cross-clamp time (mean } \pm \mathrm{SD} \\
\text { minutes) }\end{array}$ & $\begin{array}{l}50 \pm \\
15.5\end{array}$ & $70 \pm 20.5$ & 4.92 & 0.001 \\
$\begin{array}{l}\text { Cardioplegia Volume } \\
\text { Total initial dose (ml) }\end{array}$ & $\begin{array}{l}954 \pm \\
235\end{array}$ & $1062 \pm 198$ & 11.09 & 0.021 \\
Antegrade-initial (ml) & $944 \pm$ & $786 \pm 295$ & 2.67 & 0.001 \\
Number of additional doses & $\begin{array}{l}1.0 \pm \\
0.4\end{array}$ & $3.2 \pm 1.3$ & 10.23 & 0.001 \\
\end{tabular}

Table 4

Postoperative outcomes.

\begin{tabular}{llll}
\hline $\mathrm{N}=80$ & & & \\
\hline Outcomes & $\begin{array}{l}\text { del Nido group } \\
(\mathrm{n}=40)\end{array}$ & $\begin{array}{l}\text { Conventional group } \\
(\mathrm{n}=40)\end{array}$ & $\begin{array}{l}\mathrm{p} \\
\text { value }\end{array}$ \\
\hline $\begin{array}{l}\text { Postoperative inotropic } \\
\quad \text { support }\end{array}$ & $26(65 \%)$ & $28(70 \%)$ & 0.152 \\
$\quad$ Number of inotropes & $1.9 \pm 1$ & $2.0 \pm 0.9$ & 0.449 \\
$\quad$ Nor adrenaline dose $(\mu / \mathrm{min})$ & $4.0 \pm 2.6$ & $3.6 \pm 2.7$ & 0.592 \\
adrenaline dose $(\mu / \mathrm{min})$ & $2.4 \pm 1.5$ & $2.7 \pm 1.5$ & 0.600 \\
$\quad$ Ventilation duration (hours) & $5.6 \pm 1.7$ & $6.8 \pm 2.2$ & 0.373 \\
$\quad$ Total PRBC Transfusion & $1.3 \pm 1.5$ & $2.3 \pm 2.4$ & 0.033 \\
$\quad$ (mean) (units) & & & \\
ICU stay (mean \pm SD days) & $1.99 \pm 0.9$ & $1.87 \pm 0.8$ & 0.530 \\
Postoperative hospital stays & $5.05 \pm 2.3$ & $4.1 \pm 1.9$ & 0.472 \\
$\quad$ (mean \pm SD days) & & & 0 \\
Intra-aortic balloon pump & $0(0 \%)$ & $0(0 \%)$ & 0 \\
In-hospital mortality & $0(0 \%)$ & $0(0 \%)$ & \\
\hline
\end{tabular}

protection with good clinical outcome. Administration of cardioplegia and frequency may vary widely between centers. Some studies have demonstrated good safety even with a single dose of cardioplegia thus reducing the cross-clamping time in order to advance surgical outcomes.

Our study main findings were that: the Del Nido cardioplegia use was associated with shorter cardiopulmonary bypass and cross clamping times, there was no any cerebrovascular accident and mortality during the post-operative period in both the Del Nido and conventional group, during an operation myocardial protection as evidenced by requirement for inotropes for circulatory support was equal in both the groups, and the Del Nido solution usage decreases the volume of packed red blood cell pints transfusion. The findings of our study are in line with previously conducted study which states that cardiopulmonary bypass time was statistically significantly shorter in the del Nido group and Del Nido cardioplegia is safe and can be used efficiently in isolated valve replacement surgery. ${ }^{17-19}$ Our study findings are also supported by recently published systematic review and meta-analysis on del Nido versus blood cardioplegia in adult cardiac surgery. ${ }^{20}$

A previous study reported that decreased administration for patients receiving the Del Nido cardioplegia ${ }^{16}$ which was inconsistent with this study as we found there was no significant statistical association between the type of cardioplegia and the possibility of receiving the RBCs transfusion. We suggest use of ultrafiltration decreases red blood transfusion when high crystalloid-based solution is used.

The myocardium of adult patients behaves differently when compared to myocardium of pediatric patients during ischemia and are often not protected well by some of the cardioplegia solutions. This may be the reason why adult patients subjected to cardiac surgical procedures have decreased recovery of ventricular function and the lesser chance of survival. ${ }^{8,9}$ The mechanism accountable for an intolerance to ischemia seems to be connected to faster buildup of intracellular $\mathrm{Ca} 2+{ }^{9-11}$ The strategies to decrease the buildup of intracellular $\mathrm{Ca} 2+$ in adult hearts would therefore advance the regaining of ventricular function after the ischemia. ${ }^{7}$

The lidocaine, which is existing in the Del Nido solution, is a common chemical but the mechanism of action is not evidently understood. Likelihoods include coronary vasodilation to advance delivery of cardioplegia solution, prevention of arrhythmias due to reperfusion, and decrease of $\mathrm{Na}+$ influx via the gap current through the arrest. During the cardioplegic arrest, membrane potential steadies at a comparatively depolarized level at which a trivial tonic inward $\mathrm{Na}+$ current is active. This window current is connected to a trivial proportion of the voltage gated $\mathrm{Na}+$ networks that are existing, open, and in the full of life state. ${ }^{12-14}$ This is a potential disadvantage of depolarizing cardioplegic arrest since $\mathrm{Na}+$ influx is understood to be the key driver of $\mathrm{Ca} 2+$ excess. $^{15}$

With an intention to optimize the potential of the Del Nido cardioplegia solution formulation, we endorsed that lidocaine moves the activation and in-activation curves for $\mathrm{Na}+$ networks in a way that decreases the possible for $\mathrm{Na}+$ window current. This may signify an imperative mechanism of benefit with the Del Nido formulation, and the lidocaine concentration in the present preparation seems to be enough.

The Del Nido cardioplegia formulation also comprises a little excess magnesium and potassium compared to the standard cardioplegia, leading in additional pronounced depolarization of membrane. This dyselectrolemia also could contribute to a more efficient arrest. Decreased spontaneous activity in the ischemic period must bound the development of intracellular acidosis, which energies the $\mathrm{Na}+$, and later $\mathrm{Ca} 2+$ influx, that leads to reperfusion ischemic injury.

The two distinct advantages of the Del Nido cardioplegia over the conventional cardioplegia are seeming from this study data. First, surgeries using the Del Nido were shorter, despite similar pre surgery risk factors, which we attribute to the condensed time needed for administration of cardioplegia. With the Del Nido formulation, the disturbance of repetitive cardioplegia administering was avoided. Repetitive administration can be cumbersome, can intrude the flow of the surgery, and could be tough to time correctly. In this setting, a single-dose agent is extremely desirable. Furthermore, the condensed cross-clamp (ischemic time) can demonstrate to have positive effects on clinical outcomes.

\section{Conclusion}

This study demonstrated that use of the Del Nido cardioplegia solution decreased the cardiopulmonary bypass and cross clamp time also the necessity for repetitive doses of cardioplegia administration. Furthermore, the additional advantage of maintaining continuity of the surgery without the necessity for recurrent cardioplegia administration cannot be ignored. The Del Nido cardioplegia solution relates to the less spontaneous action during the arrest, decreased the myocardial injury, and enhanced the functional recovery.

\section{Recommendations}

Single dose of Del Nido cardioplegia is reliable and acceptable for use, with exceptional postoperative outcomes, in mitral valve surgery. The limitations of this study are descriptive and retrospective in nature, and a small cohort size. Additional prospective long-term research studies should be carried out to discover the applications of the Del Nido cardioplegia solution and to validate this study findings.

\section{Funding}

The authors did not receive any financial support. 


\section{Declaration of competing interest}

The authors declare that they have no known competing financial interests or personal relationships that could have appeared to influence the work reported in this paper.

\section{References}

1 Nicolini F, Beghi C, Muscari C, et al. Myocardial protection in adult cardiac surgery: current options and future challenges. Eur J Cardio Thorac Surg. 2003;24:986-993.

2 Gay Jr WA, Ebert PA. Functional, metabolic, and morphologic effects of potassiuminduced cardioplegia. Surgery. 1973;74(2):284-290.

3 Braimbridge MV, Chayen J, Bitensky L, Hearse DJ, Jynge P, Cankovic DS. Cold cardioplegia or continuous coronary perfusion? J Thoracvasc Surg. 1977;74(6): 900-906.

4 Allen BS. Pediatric myocardial protection: where do we stand? J Thorac Cardiovasc Surg. 2004;128(1):11-13. https://doi.org/10.1016/j.jtcvs.2004.03.017.

5 Govindapillai A, Hua R, Rose R, Friesen CH, O'Blenes SB. Protecting the aged heart during cardiac surgery: use of del Nido cardioplegia provides superior functional recovery in isolated hearts. $J$ Thorac Cardiovasc Surg. 2013;146(4):940-948. https:// doi.org/10.1016/j.jtcvs.2013.05.032.

6 Charette K, Gerrah R, Quaegebeur J, et al. Single dose myocardial protection technique utilizing del Nido cardioplegia solution during congenital heart surgery procedures. Perfusion. 2012;27(2):98-103. https://doi.org/10.1177/ 0267659111424788.

7 Matte GS, del Nido PJ. History and use of del Nido cardioplegia solution at Boston Children's Hospital [published correction appears in J Extra Corpor Technol. 2013 Dec;45(4):262]. J Extra Corpor Technol. 2012;44(3):98-103.

8 Gravlee GP, Davis RF, Stammers AH, Ungerleider RM. Cardiopulmonary Bypass: Principles and Practice. Philadelphia: Lippincott Williams \& Wilkins; 2008.
9 Hensley FA, Martin DE, Gravlee GP. A Practical Approach to Cardiac Anesthesia. Philadelphia: Lippincott Williams \& Wilkins; 2013.

10 Vinten-Johansen J, Thourani VH. Myocardial protection: an overview. J Extra Corpor Technol. 2000;32(1):38-48.

11 Casthely, Bregman D, Marty Alan T. Cardiopulmonary bypass: physiology, related complications, and pharmacology. Chest. 1992;102(4):22.

12 William VL, Cooper T, Zafiracopoulos P, Hanlon CR. Depression of ventricular function following elective cardiac arrest with potassium citrate. Surgery. 1959;46: $792-796$.

13 Hoelscher B, Just O, Merker H. Studies by electron microscope on various forms of induced cardiac arrest in dog and rabbit. Surgery. 1961;49:492-499.

14 Midell AI, DeBoer A, Bermudez G. Postperfusion coronary ostial stenosis: incidence and significance. $J$ Thorac Cardiovasc Surg. 1976;72(1):80-85.

15 Nunn DD, Belisle CA, Lee WH. A comparative study of aortic occlusion alone and of potassium citrate arrest during cardiopulmonary bypass. Surgery. 1959 May;45(5): 848-851.

16 Guajardo Salinas GE, Nutt R, Rodriguez-Araujo G. Del Nido cardioplegia in low risk adults undergoing first time coronary artery bypass surgery. Perfusion. 2017;32(1): 68-73. https://doi.org/10.1177/0267659116661051.

17 Ucak HA, Ucak D. Single-dose del Nido cardioplegia vs. Blood cardioplegia in aortic valve replacement surgery. Braz J Cardiovasc Surg. 2020. https://doi.org/10.21470/ 1678-9741-2020-0063. published online ahead of print, 2020 Oct 28.

18 Luo H, Qi X, Shi H, et al. Single-dose del Nido cardioplegia used in adult minimally invasive valve surgery. $J$ Thorac Dis. 2019;11(6):2373-2382. https://doi.org/ 10.21037/jtd.2019.05.78.

19 Shi H, Luo H, Qi X, et al. Del Nido cardioplegia in surgery for aortic root disease: a historically controlled study. J Thorac Dis. 2020;12(8):4105-4114. https://doi.org/ 10.21037/jtd-20-1101.

20 Misra S, Srinivasan A, Jena SS, Bellapukonda S. Myocardial Protection in Adult Cardiac Surgery With del Nido Versus Blood Cardioplegia: a Systematic Review and Meta-Analysis. Heart Lung Circ. 2021;30(5):642-655. https://doi.org/10.1016/j. hlc.2020.10.016. 